\title{
Should High-Frequency Ventilation in the Adult Be Abandoned?
}

\author{
Albert P Nguyen MD, Ulrich H Schmidt MD PhD MBA, and Neil R MacIntyre MD
}

\author{
Introduction \\ The Conceptual Rationale for Using HFOV \\ The Argument for HFOV in the Adult \\ Pathophysiology Considerations \\ Outcome Data From Randomized Clinical Trials \\ The Argument for Keeping HFOV as a Viable Option in Adults With \\ Severe ARDS \\ Conceptual Arguments Remain Attractive and Are Supported By Data \\ Positive Results Have Consistently Been Reported in Infant/Pediatric \\ Trials and Small Adult Studies \\ Arguments to Abandon HFOV Focus Heavily on OSCAR/OSCILLATE, \\ Both Flawed Trials \\ If HFOV Still Has a Role, When and How Should It Be Used? \\ Summary
}

\begin{abstract}
High-frequency oscillatory ventilation (HFOV) can improve ventilation-perfusion matching without excessive alveolar tidal stretching or collapse-reopening phenomenon. This is an attractive feature in the ventilation of patients with ARDS. However, two recent large multi-center trials of HFOV failed to show benefits in this patient population. The following review addresses whether, in view of these trails, HFOV should be abandoned in the adult population? Key words: acute respiratory failure; high-frequency oscillatory ventilation. [Respir Care 2016;61(6):791-800. ( 2016 Daedalus Enterprises]
\end{abstract}

\section{Introduction}

In 1967, Ashbaugh et al ${ }^{1}$ published a case series describing a common constellation of symptoms in 12 patients with acute onset respiratory distress. The patterns, which the authors coined "respiratory-distress syndrome," included: tachypnea, lung compliance reduction, cyanosis refractory to oxygen therapy, and diffuse alveolar infil-

\footnotetext{
Drs Nguyen and Schmidt are affiliated with the Department of Anesthesiology, University of California, San Diego, California. Dr MacIntyre is affiliated with the Department of Medicine, Duke University, Durham, North Carolina.

Dr MacIntyre presented a version of this work at the 54th RESPIRATORY CARE Journal Conference, held June 5 and 6, 2015, in St. Petersburg, Florida.
}

The authors have disclosed no conflicts of interest. trates on chest roentgenogram. ${ }^{1}$ This syndrome, since retermed ARDS, has undergone periodic redefinition. In the most recent terminology, the Berlin definition ${ }^{2}$ categorizes ARDS based on the severity of hypoxia as defined by the $\mathrm{P}_{\mathrm{aO}} / \mathrm{F}_{\mathrm{IO}_{2}}$ ratio at a PEEP $\geq 5 \mathrm{~cm} \mathrm{H}_{2} \mathrm{O}$. Mild is defined as $\mathrm{P}_{\mathrm{aO}_{2}} / \mathrm{F}_{\mathrm{IO}_{2}} \leq 300 \mathrm{~mm} \mathrm{Hg}$, moderate is defined as $\mathrm{P}_{\mathrm{aO}_{2}} / \mathrm{F}_{\mathrm{IO}_{2}}$ $\leq 200 \mathrm{~mm} \mathrm{Hg}$, and severe is defined as $\mathrm{P}_{\mathrm{aO}_{2}} / \mathrm{F}_{\mathrm{IO}_{2}}$ $\leq 100 \mathrm{~mm} \mathrm{Hg}$. Included in the criteria was the occurrence of worsening respiratory symptoms within 1 week of a known insult and bilateral opacities on chest imaging. Cardiac failure is now recognized to be a potential contributor to

Correspondence: Ulrich H Schmidt MD PhD MBA, Department of Anesthesiology, University of California, San Diego, 200 West Arbor Drive, San Diego, CA 92103. E-mail address: uschmidt@ucsd.edu.

DOI: $10.4187 /$ respcare. 04584 
the development of ARDS. With the changes in definitions, the hope is to better identify and treat the syndrome.

The severe inflammatory process and diffuse endothelial and epithelial injury associated with ARDS can lead to poor outcomes. The mortality of ARDS is related to the degree of the hypoxia. With severe ARDS, mortality can be as high as $45 \% .^{2}$ Those who do survive ARDS can continue to have significant functional disabilities long after discharge from the hospital. In a prospective cohort study, 109 young (average age 45 y old) ARDS survivors were followed up to $5 \mathrm{y}$ following their discharge from the ICU. ${ }^{3}$ Depression, posttraumatic stress disorder, and persistent weakness were common features in the cohort. Many of these subjects developed pulmonary fibrotic changes that were in line with ventilator-induced lung injury (VILI).

It has been recognized that mechanical ventilation can further exacerbate (or even precipitate) ARDS. Past mechanical ventilation strategies favored large tidal volumes $\left(\mathrm{V}_{\mathrm{T}}\right)$ of up to $12-15 \mathrm{~mL} / \mathrm{kg}$ and tolerating end-inspiratory plateau pressures in excess of $35 \mathrm{~cm} \mathrm{H}_{2} \mathrm{O}$ in an attempt to improve oxygenation. ${ }^{4}$ Toward the start of the new millennium, however, there was increasing recognition that this strategy induced significant alveolar injury VILI. The mechanisms of VILI are complex but revolve around the concepts of regional alveolar overstretching and collapsereopening phenomenon.

The publication of the large National Institutes of Health ARDS Network trial in $2000^{5}$ led to significant changes in the ventilation management of patients with ARDS. From this study, targeting $\mathrm{V}_{\mathrm{T}}$ in the normal physiologic range of 4-8 $\mathrm{mL}$ per $\mathrm{kg}$ ideal body weight and limiting plateau pressures to the normal physiologic maximum of $30 \mathrm{~cm} \mathrm{H}_{2} \mathrm{O}$ resulted in a $22 \%$ reduction in mortality compared with subjects who were ventilated with large $\mathrm{V}_{\mathrm{T}} \cdot{ }^{5}$ The mortality benefits of this lung-protective strategy were further supported by a 2013 Cochrane review. ${ }^{6}$

\section{The Conceptual Rationale for Using HFOV}

High-frequency oscillatory ventilation (HFOV) is a ventilator support strategy that, in the adult, uses breathing frequencies of $180-900$ breaths/min $(3-15 \mathrm{~Hz})$ with resulting small $\mathrm{V}_{\mathrm{T}}$, often less than anatomic dead space. ${ }^{7-9}$ HFOV provides an oscillating pressure/volume waveform superimposed on a constant distending mean airway pressure $\left(\overline{\mathrm{P}}_{\mathrm{aw}}\right)$. With this pattern, HFOV can deliver a substantial $\overline{\mathrm{P}}_{\mathrm{aw}}$ to improve ventilation-perfusion matching without excessive alveolar tidal stretching or collapse reopening phenomenon. This is an attractive concept that specifically addresses VILI risk factors ${ }^{10}$ (Fig. 1).

HFOV is usually provided with a closed ventilator system and relies on a set bias flow to deliver fresh gas and remove carbon dioxide from the circuit. Unlike conventional mechanical ventilation, both the inspiratory and ex-

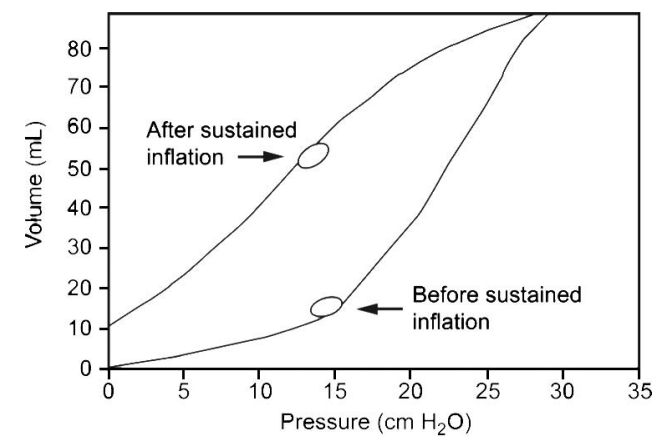

Fig. 1. Schematic drawing to illustrate the position of the dynamic loops in relation to the overall pressure-volume curve during highfrequency oscillatory ventilation before and after sustained inflation. From Reference 9, with permission.

piratory phases are active processes. $\overline{\mathrm{P}}_{\mathrm{aw}}$ is generated by manipulations of the bias flow and circuit pressure. It is often initially set $5 \mathrm{~cm} \mathrm{H} \mathrm{H}_{2} \mathrm{O}$ above the patient's $\overline{\mathrm{P}}_{\mathrm{aw}}$ while on conventional ventilation and adjusted to meet oxygenation goals. ${ }^{11}$

The oscillatory pressure swings (and thus $\mathrm{V}_{\mathrm{T}}$ ) of HFOV are generally provided by a piston whose displacement is clinician-set. The oscillating pressures in the circuit are significantly damped in alveolar regions. Indeed, the impedance in the endotracheal tube alone significantly reduces the pressure swings in the trachea to $5-16 \%$ of that in the circuit. ${ }^{12}$ As a consequence, the actual pressure swings and $\mathrm{V}_{\mathrm{T}}$ delivered to the alveoli are markedly less than in the circuit. The oscillatory pressure swings and $\mathrm{V}_{\mathrm{T}}$ can be increased by increasing the oscillator displacement (power setting), decreasing the oscillation frequency (longer inspiratory displacement time), increasing the internal diameter of the endotracheal tube, or reducing the inspiratoryexpiratory ratio. ${ }^{12}$

Because the $\mathrm{V}_{\mathrm{T}}$ levels actually reaching alveoli are usually less than dead space, HFOV relies on various mechanisms for gas exchange through the airways. ${ }^{13,14}$ Similar to conventional ventilation, inspired oxygen can travel as a bulk flow and reach proximal alveoli. Longitudinal dispersion occurs by combined convective flow and diffusion. Pendelluft arises from different alveolar emptying time and adjacent ventilation of nearby alveoli, resulting in asynchronous alveolar gas filling. Gas mixing at the smallest bronchioles occurs by molecular diffusion. Gas movement due to asymmetric velocity profiles occurs due to slower velocities along the wall of the airway compared with the center. With repeated oscillations, the center gas moves to the distal lung units, whereas the gas along the wall moves proximally. ${ }^{14}$ The heart also plays a role in gas exchange by cardiogenic mixing. Although the bias flow is important in $\mathrm{CO}_{2}$ removal, the frequency, inspiratory time, and oscillatory volume are the predominant contributors to the rate of $\mathrm{CO}_{2}$ elimination. ${ }^{12,15-18}$ 
Numerous small animal studies in the last half of the 20th century were important in elucidating the mechanisms of HFOV support, and these prompted the performance of numerous clinical trials. ${ }^{19}$ These were first performed in neonatal/pediatric populations starting in the 1970s, and subsequent meta-analyses suggested that HFOV use was associated with a significantly lower incidence of chronic lung disease. ${ }^{20}$ Application of HFOV in the adult population for ARDS required the development of more powerful devices and was first described in 1997.21 A subsequent meta-analysis of several small adult trials in 2013 suggested that HFOV may actually offer a mortality benefit. ${ }^{22}$ However, times have changed. Several new and larger trials have called into question these optimistic reports, and indeed, the role of HFOV, especially in the adult, is undergoing careful reconsideration. The sections below look at both sides of this important clinical question.

\section{The Argument for Abandoning HFOV in the Adult}

\section{Pathophysiology Considerations}

Most of our understanding of HFOV has come from small animal models and the neonatal/pediatric population, and these concepts may not apply to the much larger adult lung. ${ }^{23}$ Moreover, in some of these animal studies, potential harmful effects of HFOV were observed. For example, in canine models, significant regional differences were seen in alveolar pressure at various locations in the lungs despite having mean alveolar pressure nearly equal to the mean opening airway pressure. This resulted in the observation of distinct areas of both hyperinflation and hypoinflation. $^{24}$

In an adult sheep model, Sedeek et $\mathrm{al}^{26}$ used adult highfrequency oscillatory ventilator management strategies that were identical to the ones used in early adult clinical trials by Fort et $\mathrm{al}^{21}$ and Mehta et al. ${ }^{25}$ These investigators found that quite large $\mathrm{V}_{\mathrm{T}}$ (ie, $6 \mathrm{~mL} / \mathrm{kg}$ ) were being delivered into the proximal airways. The authors believed that the larger endotracheal tubes used in adults may have provided less attenuation of the oscillating pressures in HFOV compared with pediatric size endotracheal tubes. ${ }^{26}$ As a result, the alveoli could be overdistended and injured from large pressure swings. However, caution must be exercised to avoid overinterpreting these data because, as noted above, considerable damping of the circuit pressure and volume swings occurs in the more distal tracheobronchial tree.

As discussed earlier, improvements in the $\mathrm{P}_{\mathrm{aO}_{2}} / \mathrm{F}_{\mathrm{IO}_{2}}$ with HFOV are dependent on providing pressure above the critical opening pressure of the alveoli and maintaining pressures above this threshold to minimize cyclical opening and closing of alveoli that leads to VILI. ${ }^{10}$ However, this is not always the case. Papazian et $\mathrm{al}^{27}$ compared HFOV in both the supine and prone position with prone-conven- tional ventilation targeting $\mathrm{V}_{\mathrm{T}}$ of $6 \mathrm{~mL} / \mathrm{kg}$ in subjects with moderate ARDS. There was no significant improvement in the $\mathrm{P}_{\mathrm{aO}_{2}} / \mathrm{F}_{\mathrm{IO}_{2}}$ at $12 \mathrm{~h}$ in the supine $\mathrm{HFOV}$ arm, whereas both the prone conventional ventilation and prone HFOV groups showed a significant improvement (from $138 \pm 58$ to $217 \pm 110 \mathrm{~mm} \mathrm{Hg}[P<.001]$ and from $126 \pm 40 \mathrm{~mm} \mathrm{Hg}$ to $227 \pm 64 \mathrm{~mm} \mathrm{Hg}[P<.001]$, respectively) at $12 \mathrm{~h}$. Bronchoalveolar lavage was done before and $12 \mathrm{~h}$ after randomization. In both HFOV groups, cytokine interleukin-8 increased significantly from baseline levels as well as compared with the prone conventional ventilation arm. The prone conventional ventilation arm saw a decrease in concentration compared with its baseline level. The neutrophil concentration was lower in the prone conventional ventilation group compared with both HFOV groups. This study suggests that HFOV subjects alveoli to harmful cyclical opening and closing as interleukin- 8 is up-regulated when epithelial cells are subjected to cyclical overstretching.

Conventional mechanical ventilation can often achieve improvements in $\mathrm{P}_{\mathrm{aO}_{2}} / \mathrm{F}_{\mathrm{IO}_{2}}$ similar to HFOV, depending upon settings. For example, in rabbit lung injury models, utilizing a short lung recruitment maneuver followed by $\mathrm{V}_{\mathrm{T}}<5 \mathrm{~mL} / \mathrm{kg}$ and PEEP adjusted to be above the lung's critical closing pressure was found to improve the $\mathrm{P}_{\mathrm{aO}_{2}} / \mathrm{F}_{\mathrm{IO}_{2}}$ similar to HFOV. In addition, lung histology in this group showed minimal airway injury. ${ }^{9}$ This was also supported by the work of Vazquez de Anda et $\mathrm{a}^{28}$ in rats where high PEEP and low $\mathrm{V}_{\mathrm{T}}$ improved oxygenation but also reduced the influx of alveolar proteins as compared with HFOV.

Right ventricular dysfunction is a known complication of ARDS, and the high $\overline{\mathrm{P}}_{\mathrm{aw}}$ and general absence of spontaneous inspiratory efforts during HFOV can exacerbate this problem further, especially under fluid-depleted conditions. Guervilly et al ${ }^{29}$ evaluated right-ventricular function using transesophageal echocardiography in adult subjects with moderate to severe ARDS receiving HFOV. At baseline, over half of their subjects had right-ventricular dysfunction (defined by a right-ventricular end-diastolic area to left-ventricular end-diastolic area ratio $>0.6$ ), and $25 \%$ had right-ventricular failure (defined by right-ventricular end-diastolic area/left-ventricular end-diastolic area $>0.9$ ). Increasing the $\overline{\mathrm{P}}_{\mathrm{aw}}>5 \mathrm{~cm} \mathrm{H}_{2} \mathrm{O}$ to improve the $\mathrm{P}_{\mathrm{aO}_{2}} / \mathrm{F}_{\mathrm{IO}_{2}}$ was found to worsen the right-ventricular enddiastolic area/left-ventricular end-diastolic area by as much as $40 \%$. Cardiac index was also found to be significantly reduced due to increasing $\overline{\mathrm{P}}_{\mathrm{aw}}$ and worsening right-ventricular function. As a consequence, vasopressor requirements may be higher in HFOV patients. These hemodynamic issues are important, given that death associated with HFOV appears to be more related to end-organ failure and hemodynamic compromise as opposed to failure to oxygenate. ${ }^{30}$

High-frequency oscillatory ventilation requires synchrony with any existing patient breathing efforts. Spon- 
taneous respiration results in a reduced airway pressure that the ventilator may interpret as a circuit disconnect, subsequently stopping ventilation. ${ }^{26}$ In addition, inadequate synchrony results in oxygen desaturation, patient discomfort, and barotrauma. To achieve synchrony, heavy sedation and the use of continuous neuromuscular blockade are often required. Indeed, in most of the clinical trials described below, the sedation needs and requirements for neuromuscular blockade were almost always higher in the HFOV group versus the control group.

\section{Outcome Data From Randomized Clinical Trials}

Although several small trials of HFOV versus conventional ventilation showed promise, ${ }^{22}$ recently, 2 large trials have been published that have concluded no benefit and possibly harm with the use of HFOV.

The OSCILLATE and OSCAR trials were 2 large multicenter trials published in 2013 comparing HFOV with conventional mechanical ventilation in moderate to severe ARDS. In the OSCILLATE trial, ${ }^{31}$ subjects of similar severity of ARDS were included $\left(\mathrm{P}_{\mathrm{aO}_{2}} / \mathrm{F}_{\mathrm{IO}_{2}}\right.$ of $113 \pm 38 \mathrm{~mm} \mathrm{Hg}$ in the conventional ventilation group and $113 \pm 37 \mathrm{~mm} \mathrm{Hg}$ in the HFOV group); however, subjects who had been ventilated for $>72 \mathrm{~h}$ were excluded. The OSCAR trial ${ }^{32}$ included subjects ventilated up to $7 \mathrm{~d}$ with similar ARDS severity; $114 \pm 38 \mathrm{~mm} \mathrm{Hg}$ versus $121 \pm 46 \mathrm{~mm} \mathrm{Hg}$ in conventional ventilation versus HFOV groups, respectively. Rather surprisingly, the OSCILLATE trial was prematurely stopped due to worse outcomes in the HFOV group. The mortality in the HFOV group was higher both for in hospital (47\% vs 35\%) and at $28 \mathrm{~d}$ (40\% vs $20 \%$ ). Although the conventional ventilation group had a higher number of subjects with refractory hypoxemia, the overall percentage of subjects dying due to this was similar between the groups. The OSCAR trial was completed as intended; however, it demonstrated no difference in mortality between the 2 groups ( $41.7 \%$ for HFOV vs $41.1 \%$ for conventional ventilation).

Interestingly, the mortality in the conventional ventilation strategy with OSCAR was much higher than the conventional ventilation group in OSCILLATE, despite the fact that the disease severity in the OSCILLATE group was higher (Acute Physiology and Chronic Health Evaluation [APACHE] II score $29 \pm 7$ vs $21.7 \pm 6.1$ ). An explanation for the mortality difference may lie in the manner in which the conventional groups were ventilated. The OSCILLATE conventional group received lower $\mathrm{V}_{\mathrm{T}}$ of $7.1 \pm 1.8 \mathrm{~mL} / \mathrm{kg}$, whereas the OSCAR conventional ventilation subjects had on average higher $\mathrm{V}_{\mathrm{T}}$ of $8.3 \pm 3.5 \mathrm{~mL} / \mathrm{kg}$. This supports the notion that lower $\mathrm{V}_{\mathrm{T}}$ ventilation conveys a survival advantage in moderate to severe ARDS and suggests that a significant mortality dif- ference favoring conventional ventilation might have been seen in the OSCAR trial if the conventional ventilation arm used lower $\mathrm{V}_{\mathrm{T}}$. A more recent meta-analysis that included these new trials has now concluded that there is no benefit to HFOV in the adult. ${ }^{33}$

So why are the results of these more recent trials at odds with previous animal and pediatric data? Perhaps there are effects of HFOV in the adult lung that have not been fully appreciated in the past. High distending pressures are known to put the lung at risk for injury and cardiac compromise, and thus the very mechanism that improves $\mathrm{P}_{\mathrm{aO}} / \mathrm{F}_{\mathrm{IO}_{2}}$ with HFOV may contribute to harm. Moreover, in ARDS, the lungs are affected in a heterogeneous manner, with areas of damaged and collapsed alveoli intermixed with open alveoli. High intrathoracic pressures may thus lead to further regional lung injury. HFOV settings in adults are also different from those of pediatric patients. Lower frequencies $(4-8 \mathrm{~Hz}$ in adult vs $8-12 \mathrm{~Hz}$ in pediatric patients) and pressure amplitudes of up to $60 \mathrm{~cm} \mathrm{H}_{2} \mathrm{O}$ are often used in adults. ${ }^{34}$ This can translate into larger delivered $\mathrm{V}_{\mathrm{T}}$ in the adult. In a retrospective analysis of 156 subjects, Mehta et $\mathrm{al}^{25}$ observed that $>20 \%$ of their subjects developed pneumothoraces on HFOV while noting that barotrauma rates in conventional mechanical ventilation ranged from 7 to $14 \%$. In the OSCILLATE trial, $18 \%$ in the HFOV arm developed new barotrauma after being switched from conventional ventilation. ${ }^{31}$

As noted above, the need for sedation and neuromuscular blockade when using HFOV in the adult could also contribute to adverse outcomes. In the Multi-Center Oscillatory Ventilation for Acute Respiratory Distress Syndrome Trial (MOAT), ${ }^{35}$ all subjects in the HFOV arm were paralyzed as well as $90 \%$ of the cohort in the study by Mehta et al. ${ }^{25}$ In the OSCAR trial, over half in the HFOV group required neuromuscular blockade, which was more than the conventional group, and required paralysis on average half a day longer than the control group. ${ }^{32}$ In the OSCILLATE trial, significantly more subjects in the HFOV arm required paralysis $(83 \%$ vs $43 \%$ ) for an average of $3 \mathrm{~d}$, which is $1 \mathrm{~d}$ longer than the control. ${ }^{31}$

In summary, HFOV should provide an ideal mode of ventilation for diffuse lung injury. However, this has not been the case in the adult population. This may be due to poorly understood effects of the HFOV ventilator pattern on injured lung units. It may also reflect cardiovascular effects as well as the need for excessive sedation, vasopressors, and neuromuscular blockade agents. Regardless, because there is no clear survival benefit and a possible higher risk for harm, a strong argument can be made that HFOV should not be used for adults with ARDS. 


\section{The Argument for Keeping HFOV as a Viable Option in Adults With Severe ARDS}

\section{Conceptual Arguments Remain Attractive and Are Supported By Data}

The conceptual lung-protective benefits of HFOV have been supported by numerous animal studies. ${ }^{19,36} \mathrm{~A}$ particularly interesting report is that of Goddon et al, ${ }^{37}$ who obtained static pressure-volume curves in anesthetized sheep before and after saline-induced lung injury. The authors measured changes in $\overline{\mathrm{P}}_{\mathrm{aw}}$ with oxygenation and compared it with the static pressure-volume curve. They found that the $\overline{\mathrm{P}}_{\mathrm{aw}}$ above the lower inflection point resulted in improvements in oxygenation and reached an optimum level when the $\overline{\mathrm{P}}_{\mathrm{aw}}$ approached the upper inflection point. They did not find any further benefit in oxygenation with going beyond the upper inflection point. Going beyond this point, they concluded, was where alveoli distention occurred. This has been seen in other studies and supported with computed tomographic imaging. ${ }^{38-40}$

Data from extensive studies in rabbits by several authors have also been enlightening. Injured rabbit lungs ventilated with $\mathrm{HFOV}$ demonstrated that increases in $\overline{\mathrm{P}}_{\mathrm{aw}}$ resulted in linear oxygenation improvements with lung volume expansion. Bronchoalveolar lavage samples from these lung-injured rabbit models were found to have lower concentrations of polymorphonuclear neutrophils and less expression of inflammatory markers, such as tumor necrosis factor- $\alpha$ prostaglandins and platelet-activating factors, compared with conventional mechanical ventilation. ${ }^{41,42}$ Perhaps more importantly, a series of rabbit experiments by Froese and Bryan ${ }^{36}$ consistently showed improved survival with HFOV. As we slowly unravel all of the mechanisms of VILI, the concepts underlying HFOV applications remain attractive.

\section{Positive Results Have Consistently Been Reported in Infant/Pediatric Trials and Small Adult Studies}

Multiple trials of HFOV in infant/pediatric populations have consistently shown that HFOV can be safely applied and is generally associated with improved longterm outcomes (ie, bronchopulmonary dysplasia and chronic lung disease). ${ }^{20,43}$ Admittedly, a few trials are negative, but only one, the HIFI trial, actually suggested harm from HFOV. ${ }^{20}$ This trial, however, has been heavily criticized because of its unfamiliar devices and strategies, minimizing rather than optimizing mean airway pressure. A recent meta-analysis has concluded that HFOV use is associated with important clinical end points in neonatal/pediatric subjects.

There is much less experience with HFOV in adults than in infant/pediatric populations because devices pow- erful enough to provide effective gas exchange in adults took longer to develop. There is no question that HFOV in adult respiratory failure has the ability to improve oxygenation. Multiple retrospective studies have observed this phenomenon. ${ }^{25,43,44}$ Mehta et al ${ }^{25}$ found a $70 \%$ improvement in oxygenation with the initiation of HFOV for severe ARDS. Randomized trials also supported this observation. The MOAT trial saw the $\mathrm{P}_{\mathrm{aO}_{2}} / \mathrm{F}_{\mathrm{IO}_{2}}$ rapidly improve from $114 \pm 37$ to $205 \pm 61 \mathrm{~mm} \mathrm{Hg} 16 \mathrm{~h}$ after initiation compared with $146 \pm 56 \mathrm{~mm} \mathrm{Hg}$ from $111 \pm 42 \mathrm{~mm} \mathrm{Hg}$ in the conventional group. ${ }^{35}$

Whether these gas exchange improvements translate into improved outcomes remains controversial. Small randomized controlled trials have attempted to answer this question with equivocal results. Until 2013, the MOAT trial ${ }^{35}$ was the largest randomized controlled trial and demonstrated a $30-\mathrm{d}$ mortality of $37 \%$ for HFOV versus $52 \%$ for the conventional ventilation arm. However, this difference was considered nonsignificant $(P=.10)$. As noted above, when taken together, a meta-analysis of these small pre2013 trials suggested a mortality benefit to HFOV. ${ }^{22}$ A common concern in these trials was that the conventional ventilation comparison group was usually not managed in a true lung-protective management algorithm. Nevertheless, the concept that HFOV could be effective in severe ARDS has some reasonably supportive clinical data.

\section{Arguments to Abandon HFOV Focus Heavily on OSCAR/OSCILLATE, Both Flawed Trials}

As noted above, HFOV settings are often counterintuitive; $\mathrm{CO}_{2}$ clearance is driven largely by the power setting and is actually a function of the inverse of frequency (lower frequencies result in larger $\mathrm{V}_{\mathrm{T}}$ with HFOV devices). Moreover, oxygenation depends on high constant distending pressures that can seriously impair cardiac filling and increase right-ventricular afterload. These features demand experienced operators who have a good understanding of pulmonary physiology, cardiopulmonary interactions, and the operational characteristics of the HFOV device.

Unfortunately, in both the OSCAR and OSCILLATE trials described above, ${ }^{31,32}$ many centers were involved that had only limited HFOV experience. Although both studies claim to have trained leadership personnel in all sites, the necessary $24 / 7$ coverage by experts was often lacking. OSCAR was further hampered by the use of a new HFOV device that very few had ever operated before. This inexperience problem may have had even more impact in OSCILLATE, where $>70 \%$ of the population was in shock at study entry and mean airway pressures were suddenly increased in the HFOV group from 20 to $>30 \mathrm{~cm} \mathrm{H}_{2} \mathrm{O}$. Interestingly, despite this dramatic increase in $\overline{\mathrm{P}}_{\mathrm{aw}}$, HFOV subjects in OSCILLATE did not have a change in central venous pressure from pre-randomization 
values suggesting preload impairment. The mixture of high mean airway pressures, poor cardiac function, and inexperienced clinicians probably had serious consequences. Taken together, the inexperience in these 2 trials, coupled with the challenges of new devices and hemodynamically compromised subjects, undoubtedly contributed to many of the adverse outcomes. It is important to remember that a clinical trial of a device requires optimal operation of the device and is thus orders of magnitude more complex to accomplish than a simple drug versus placebo clinical trial.

Both OSCAR and OSCILLATE also recruited subjects for whom HFOV was probably not needed. Bollen et al, ${ }^{45}$ in a review of infant/pediatric HFOV studies done over the last few decades, nicely demonstrated that as conventional lung-protective strategies were being introduced, the benefits to HFOV in clinical trials became less. This would suggest the HFOV probably adds little to effective conventional lung-protective ventilator support. Rather, HFOV should be considered a strategy to extend lung-protective support to sicker patients unable to be safely supported with conventional ventilation. HFOV logically should thus be reserved for those patients not in whom conventional ventilation is working, but in whom conventional ventilation is failing. In both OSCAR and OSCILLATE, the average entry $\mathrm{P}_{\mathrm{aO}_{2}} / \mathrm{F}_{\mathrm{IO}_{2}}$ was well over 100 , which translates into a $\mathrm{P}_{\mathrm{aO}_{2}}$ of $>60 \mathrm{~mm} \mathrm{Hg}$ with an $\mathrm{F}_{\mathrm{IO}_{2}}$ of $<0.6$, both in the setting of plateau pressures well below $30 \mathrm{~cm} \mathrm{H}_{2} \mathrm{O}$, clearly acceptable parameters for effective lung-protective ventilation. Indeed, in OSCILLATE, the included population was actually more of a hemodynamically compromised population than a respiratory failure population. Exposing patients properly supported safely with conventional ventilation to HFOV is not likely to provide much benefit and, as noted above, could cause harm in the wrong hands (and probably did).

This selection process was even further complicated in OSCILLATE, where 72 subjects were excluded because their physicians felt that HFOV was required and randomization would be unethical. Thus, the very patients these trials should have studied were systematically excluded. Finally, the crossover process confuses interpretation. In OSCILLATE, 31 subjects were switched from conventional ventilation to HFOV, presumably because they were failing conventional ventilation. Because it was an intention-to-treat analysis, any benefit of HFOV in these subjects would have improved conventional ventilation outcomes.

Taken together, these concerns cast serious doubt on the generalizability of OSCAR and OSCILLATE to most ICU settings managing patients with severe ARDS. Abandoning HFOV based solely on these results seems premature.

\section{If HFOV Still Has a Role, When and How Should It Be Used?}

For HFOV to be a safe and effective therapy in ARDS, it needs to be used in the right patient (severe hypoxemic respiratory failure, failing conventional ventilation), with the right expertise and device settings, and with the right hemodynamic monitoring/management strategy. Another important consideration is knowing when to stop HFOV as ineffective. In general, observational studies suggest that if HFOV is going to be effective, gas exchange improvements will occur over the first 6-12 h. If this does not occur, the likelihood of HFOV success is low, and alternative rescue strategies, such as extracorporeal membrane oxygenation, should be considered.

\section{Summary}

Managing severe hypoxemic respiratory failure involves managing competing goals, supporting gas exchange while not harming the lungs or cardiovascular system. HFOV has theoretical beneficial features that might accomplish this, but outcome benefits, especially in the adult, have been difficult to demonstrate. Indeed, HFOV may actually be associated with harm in the adult. Whether this reflects inherent problems with the HFOV ventilator pattern or reflects poor management strategies in those using HFOV (or both) is unclear. Regardless, if HFOV is still to be considered a viable option, it should be reserved for those failing conventional ventilation and applied by clinicians with considerable experience with the device.

\section{REFERENCES}

1. Ashbaugh DG, Bigelow DB, Petty TL, Levin BE. Acute respiratory distress in adults. Lancet 1967;2(7511):319-323.

2. ARDS Definition Task Force, Ranieri VM, Rubenfeld GD, Thompson BT, Ferguson ND, Caldwell E, et al. Acute respiratory distress syndrome: the Berlin definition. JAMA 2012;307(23):2526-2533.

3. Herridge MS, Tansey CM, Matté A, Tomlinson G, Diaz-Granados $\mathrm{N}$, Cooper A, et al. Functional disability 5 years after acute respiratory distress syndrome. N Engl J Med 2011;364(14):1293-1304.

4. Brochard L, Roudot-Thoraval F, Roupie E, Delclaux C, Chastre J, Fernandez-Mondéjar E, et al. Tidal volume reduction for prevention of ventilator-induced lung injury in acute respiratory distress syndrome. Am J Respir Crit Care Med 1998;158(6):1831-1838.

5. Acute Respiratory Distress Syndrome Network. Ventilation with lower tidal volumes as compared with traditional volumes for acute lung injury and the acute respiratory distress syndrome. N Engl J Med 2000;342(18):1301-1308.

6. Petrucci N, De Feo C. Lung protective ventilation strategy for the acute respiratory distress syndrome. Cochrane Database Syst Rev. 2013;(2):CD003844.

7. Krishnan JA, Brower RG. High-frequency ventilation for acute lung injury and ARDS. Chest 2000;118(3):795-807.

8. Chan KPW, Stewart TE, Mehta S. High-frequency oscillatory ventilation for adult patients with ARDS. Chest 2007;131(6):1907-1916. 


\section{Should HFOV in the Adult Be Abandoned?}

9. Rimensberger PC, Pache JC, McKerlie C, Frndova H, Cox PN. Lung recruitment and lung volume maintenance: a strategy for improving oxygenation and preventing lung injury during both conventional mechanical ventilation and high-frequency oscillation. Intensive Care Med 2000;26(6):745-755.

10. Imai Y, Slutsky AS. High-frequency oscillatory ventilation and ventilator-induced lung injury. Crit Care Med 2005;33(3 Suppl):S129-S134.

11. David M, Weiler N, Heinrichs W, Neumann M, Joost T, Markstaller K, Eberle B. High frequency oscillatory ventilation in adult acute respiratory distress syndrome. Intensive Care Med 2003;29(10):1656-1665.

12. Pillow JJ, Neil H, Wilkinson MH, Ramsden CA. Effect of I/E ratio on mean alveolar pressure during high-frequency oscillatory ventilation. J Appl Physiol 1999;87(1):407-414.

13. Lunkenheimer PP, Rafflenbeul W, Keller H, Frank I, Dickhut HH, Fuhrmann C. Application of transtracheal pressure oscillations as a modification of "diffusing respiration". Br J Anaesth 1972;44(6):627.

14. Chang HK. Mechanisms of gas transport during ventilation by high frequency oscillation. J Appl Physiol Respir Environ Exerc Physiol 1984;56(3):553-563.

15. Rossing TH, Slutsky AS, Leher JL, Lehr JL, Drinker PA, Kamm R, Drazen JM. Tidal volume and frequency dependence of carbon dioxide elimination by high-frequency ventilation. N Engl J Med 1981; 305(23):1375-1379.

16. Goffi A, Ferguson ND. High-frequency oscillatory ventilation for early acute respiratory distress syndrome in adults. Curr Opin Crit Care 2014;20(1):77-85.

17. Hager DN, Fessler HE, Kaczka DW, Shanholtz CB, Fuld MK, Simon BA, Brower RG. Tidal volume delivery during high-frequency oscillatory ventilation in adults with acute respiratory distress syndrome. Crit Care Med 2007;35(6):1522-1529.

18. Isabey D, Harf A, Chang HK. Alveolar ventilation during highfrequency oscillation: core dead space concept. J Appl Physiol Respir Environ Exerc Physiol 1984;56(3):700-707.

19. Vitali SH, Arnold JH. Bench-to-bedside review: ventilator strategies to reduce lung injury: lessons from pediatric and neonatal intensive care. Crit Care 2005;9(2):177-183.

20. Cools F, Offringa M, Askie LM. Elective high frequency oscillatory ventilation versus conventional ventilation for acute pulmonary dysfunction in preterm infants. Cochrane Database Syst Rev 2015;(3): CD000104.

21. Fort P, Farmer C, Westerman J, Johannigman J, Beninati W, Dolan S, Derdak S. High-frequency oscillatory ventilation for adult respiratory distress syndrome: a pilot study. Crit Care Med 1997;25(6): 937-947.

22. Sud S, Sud M, Friedrich JO, Wunsch H, Meade MO, Ferguson ND, Adhikari NK. High-frequency ventilation versus conventional ventilation for treatment of acute lung injury and acute respiratory distress syndrome. Cochrane Database Syst Rev 2013;(2):CD004085.

23. Kacmarek RM, Malhotra A. High-frequency oscillatory ventilation: what large-animal studies have taught us! Crit Care Med 2005;33(3 Suppl):S148-S154.

24. Allen JL, Frantz ID 3rd, Fredberg JJ. Heterogeneity of mean alveolar pressure during high-frequency oscillations. J Appl Physiol 1987; 62(1):223-228.

25. Mehta S, Granton J, MacDonald RJ, Bowman D, Matte-Martyn A, Bachman T, et al. High-frequency oscillatory ventilation in adults: the Toronto experience. Chest 2004;126(2):518-527.

26. Sedeek KA, Takeuchi M, Suchodolski K, Kacmarek RM. Determinants of tidal volume during high-frequency oscillation. Crit Care Med 2003;31(1):227-231.

27. Papazian L, Gainnier M, Marin V, Donati S, Arnal JM, Demory D, et al. Comparison of prone positioning and high-frequency oscillatory ventilation in patients with acute respiratory distress syndrome. Crit Care Med 2005;33(10):2162-2171
28. Vazquez de Anda GF, Gommers D, Verbrugge SJC, De Jaegere A, Lachmann B. Mechanical ventilation with high positive end-expiratory pressure and small driving pressure amplitude is as effective as highfrequency oscillatory ventilation to preserve the function of exogenous surfactant in lung-lavaged rats. Crit Care Med 2000;28(8):2921-2925.

29. Guervilly C, Forel JM, Hraiech S, Demory D, Allardet-Servent J, Adda M., et al. Right ventricular function during high-frequency oscillatory ventilation in adults with acute respiratory distress syndrome. Crit Care Med 2012;40(5):1539-1545.

30. Malhotra A, Drazen JM. High-frequency oscillatory ventilation on shaky ground. N Engl J Med 2013;368(9):863-865.

31. Ferguson ND, Cook DJ, Guyatt GH, Mehta S, Hand L, Austin P, et al. High-frequency oscillation in early acute respiratory distress syndrome. N Engl J Med 2013;368(9):795-805.

32. Young D, Lamb SE, Shah S, MacKenzie I, Tunnicliffe W, Lall R, et al. High-frequency oscillation for acute respiratory distress syndrome. N Engl J Med 2013;368(9):806-813.

33. Maitra S, Bhattacharjee S, Khanna P, Baidya DK. High-frequency ventilation does not provide mortality benefit in comparison with conventional lung-protective ventilation in acute respiratory distress syndrome: a meta-analysis of the randomized controlled trials. Anesthesiology 2015;122(4):841-851.

34. Chan KPW, Stewart TE. Clinical use of high-frequency oscillatory ventilation in adult patients with acute respiratory distress syndrome. Crit Care Med 2005;33(3 Suppl):S170-S174.

35. Derdak S, Mehta S, Stewart TE, Smith T, Rogers M, Buchman TG, et al. High-frequency oscillatory ventilation for acute respiratory distress syndrome in adults: a randomized, controlled trial. Am J Respir Crit Care Med 2002;166(6):801-808.

36. Froese AB, Bryan AC. High frequency ventilation. Am Rev Respir Dis 1987;135(6):1363-1374.

37. Goddon S, Fujino Y, Hromi JM, Kacmarek RM. Optimal mean airway pressure during high-frequency oscillation predicted by the pressure-volume curve. Anesthesiology 2001;94(5):862-869.

38. Kolton M, Cattran CB, Kent G, Volgyesi G, Froese AB, Bryan AC. Oxygenation during high-frequency ventilation compared with conventional mechanical ventilation in two models of lung injury. Anesth Analg 1982;61(4):323-332.

39. Luecke T, Meinhardt JP, Hermann P, Herrmann P, Weisser G, Pelosi $\mathrm{P}$, Quintel M. Setting mean airway pressure during high-frequency oscillatory ventilation according to the static pressure-volume curve in surfactant-deficient lung injury: a computed tomography study. Anesthesiology 2003;99(6):1313-1322.

40. Luecke T, Herrmann P, Kraincuk P, Pelosi P. Computed tomography scan assessment of lung volume and recruitment during high-frequency oscillatory ventilation. Crit Care Med 2005;33(3 Suppl):S155-S162.

41. Takata M, Abe J, Tanaka H, Kitano Y, Doi S, Kohsaka T, Miyasaka $\mathrm{K}$. Intraalveolar expression of tumor necrosis factor-gene during conventional and high-frequency ventilation. Am J Respir Crit Care Med 1997;156(1):272-279.

42. Suzuki H, Papazoglou K, Bryan AC. Relationship between $\mathrm{P}_{\mathrm{aO}_{2}}$ and lung volume during high frequency oscillatory ventilation. Acta Paediatr Jpn 1992;34(5):494-500.

43. Froese AB, Kinsella JP. High-frequency oscillatory ventilation: lessons from the neonatal/pediatric experience. Crit Care Med 2005; 33(3 Suppl):S115-S121.

44. Andersen FA,Guttormsen AB, Flaatten HK. High frequency oscillatory ventilation in adult patients with acute respiratory distress syndrome: a retrospective study. Acta Anaesthesiol Scand 2002; 46(9):1082-1088.

45. Bollen CW, Uiterwaal CS, van Vught AJ. Meta-regression analysis of high-frequency ventilation vs conventional ventilation in infant respiratory distress syndrome. Intensive Care Med 2007;33(4):680-688. 


\section{Discussion}

Hess: An observation I was thinking of as you were going through this, Neil [MacIntyre]. This morning there were a number of topics where we said 'we need RCTs'. And now for this topic we have randomized controlled trials (RCTs) and you're arguing that we should not believe the RCTs but we should take the observational evidence.

MacIntyre: RCTs, while being important tools to evaluate innovations, have important limitations. The results really only apply to the specific population studied (often a small fraction of the disease of interest) and only to the specific intervention strategy. This last point is particularly important in complex interventions like mechanical ventilation where potential settings and management strategies can be quite variable. High-frequency oscillatory ventilation (HFOV) is certainly not an on-off switch and involves not only numerous specific ventilator adjustments but also adjustments in other aspects of management (eg, fluids, pressors) that clearly can impact results. I really think it is important to do RCTs and try to control them as best you can but I think you have to be really careful in extrapolating the results of an RCT where there are so many variables involved into a blanket clinical recommendation. My point is that both OSCAR ${ }^{1}$ and OSCILLATE$^{2}$ evaluated only two specific HFOV management strategies in selected populations. To draw the conclusion that HFOV managed differently in different patients is necessarily harmful seems excessive.

Branson: How many people around the table used the oscillator in your ICU before these two trials came out? Five. How many use it less now?

Kacmarek: Who does not use it all?
MacIntyre: I would say, how many are still using it? I suspect OSCAR ${ }^{1}$ and OSCILLATE2 have stopped people from initiating HFOV programs. But actually I think the growing use of venovenous extracorporeal membrane oxygenation (VV-ECMO) is driving, at least in my institution, the use of HFOV down.

Branson: I disagree with this idea that the 75 patients who were excluded, because if certain people were here they'd say 75 patients couldn't come off airway pressure release ventilation (APRV) to be randomized into the trial, so that's a bias. But it's not an explanation. The control group in MOAT II $^{3}$ was, by far, crazier and less controlled than anything that happened in OSCAR $^{1}$ or OSCILLATE. ${ }^{2}$ $I^{\prime} d$ explain the reason that $\mathrm{OSCAR}^{1}$ was better than OSCILLATE² was because of the ventilator. The ventilator that was used in OSCAR $^{1}$ has a demand valve, a normal circuit, can do conventional ventilation, doesn't make a lot of noise and allows the patient to breathe spontaneously and they probably didn't need as much sedation or fluid or vasopressors. That could be the explanation why OSCAR ${ }^{1}$ was equivalent and OSCILLATE ${ }^{2}$ was worse.

MacIntyre: A reasonable speculation.

Kacmarek: However, look at the mortality in the HFOV group in OSCAR $^{1}$ and OSCILLATE ${ }^{2}$ it was the same. The difference was the mortality in the control group. As you said, the control group in OSCAR ${ }^{1}$ was not well defined. People did whatever they wanted to. The reason OSCAR ${ }^{1}$ came out equivalent is because of poorer control group ventilation: $41 \%$ mortality in the control group. So, I think it's not that OSCAR was better, it's that ventilation in the control group was not well defined.
MacIntyre: It goes back to my comments to Dean. Clinical RCTs in complex systems are so difficult to interpret because there are so many potential variables that can change.

Branson: If I remember right, the mortality rate in the control group in MOAT II ${ }^{3}$ was $60 \%$.

MacIntyre: Yes, it was over 50\%.

Branson: Maybe the issue here is all explained by what happens in the control group.

Kacmarek: I agree completely that it's a problem with the control group. You said there's supportive evidence, what is that supportive evidence to use HFOV? The Sud $\mathrm{RCT}^{4}$, half of those are abstracts that never got submitted to peer review. The other half of those subjects are the MOAT $\mathrm{II}^{3}$ trial which was a terrible trial from the control group perspective.

MacIntyre: Fair enough.

Kacmarek: Again, what evidence are you talking about?

MacIntyre: I think the evidence applicable to human beings largely comes from the pediatric world.

Kacmarek: There is only one $\mathrm{RCT}^{5}$ in pediatrics. The one done by John Arnold's group 5 at Boston Children's in which there was no difference in any variable and in which they don't even tell you the actual pressures, volumes, or approach that was used in either group. They tell you the theoretical settings but they don't give you any actual data.

MacIntyre: Well, there are probably 20 trials in pediatric world. I wasn't prepared to review all of them.

Kacmarek: But there's not a trial in the neonatal world that shows change in mortality. 
MacIntyre: The most significant end-point in most of these trials - probably all of them - is development of chronic lung disease. Which I would interpret as less ventilator-induced lung injury.

Kacmarek: I would agree with you but if you look at the specific trials where that was the case, conventional mechanical ventilation was done in a non-lung protective approach. If you look at the more current trials where the conventional arm was the way you'd expect it to be you don't have the same level of chronic lung disease.

MacIntyre: Bollen et $\mathrm{al}^{6}$ showed that over the life history of HFOV two big events came along: surfactant and lung-protective ventilation and both of those reduced the benefit of HFOV over conventional ventilation. I won't argue that.

Mireles-Cabodevila: I have three issues with the trials - the first is the protocol. They did test it in some group of subjects in the OSCILLATE ${ }^{2}$ trial and then applied it. However, especially with HFOV, it is not the mode but how you apply it; I think more work was needed to define the best protocol. The second is that the question they ask is not, "does the oscillator work', but 'does it work in early ARDS overall'. These trials did not answer whether we should use HFOV as a rescue therapy. The trials were designed differently. The OSCAR ${ }^{1}$ study was a pragmatic trial and had little exclusion criteria. A negative result in a trial with a pragmatic design doesn't mean the intervention is ineffective. If it was positive it would be very good. The OSCILLATE ${ }^{2}$ trial is an explanatory trial, with more exclusion criteria and expert centers. A negative result in an explanatory trial means the intervention is not effective. However, in this trial the only thing all centers were experts on was lung-protective ventilation, the HFOV protocol was not universal to all centers. It takes time to master a protocol. I doubt we will have any further trials, although one on rescue HFOV in subjects who have refractory hypoxemia or dangerous ventilation may be helpful.

MacIntyre: That's where it ought to be used in my opinion. The Lachman approach strategy of opening the lung up as applied to that trial ${ }^{7}$ think was too aggressive, especially in a population when $2 / 3$ were in shock. I think that's a bad combination.

Mireles-Cabodevila: We end up only using HFOV for patients who cannot go into ECMO. Which is where we were using it before.

Marini: Neil, very nice. An interesting side issue is that effective driving pressure should have been quite low in those HFOV trials. Was lung function actually deteriorating in the dying subjects? If HFOV was doing damage to the lung you would expect that oxygenation would be crashing, wouldn't you?

Macintyre: Ihope I'm not misspeaking, but as I understand the Canadian group's explanation of why OSCILLATE$^{2}$ failed was hemodynamics.

Marini: The other interesting thing to me, and I've never quite understood it, is the total minute ventilation that's moving in and out of the patient is high. Right?

MacIntyre: Well, the total ventilation moving in and out of the circuit and major airways is high. What's actually taking place at the alveolar level, I'm not sure anybody really knows.

\section{Marini: No.}

MacIntyre: It's very confusing because you can get large tidal pressure and volume swings in the circuit but at the alveolar level these swings are often quite small.

Marini: I'm thinking about the total minute ventilation coming in and out of the lungs and if that has any relation to dead space. Because if it does, then several things come to mind. The $\mathrm{V}_{\mathrm{D}} / \mathrm{V}_{\mathrm{T}}$ ratio might be quite high in HFOV. People don't talk much about that.

MacIntyre: I'm not sure what deadspace means when dealing with nonconvective gas transport mechanism. You have important $\mathrm{O}_{2}$ and $\mathrm{CO}_{2}$ concentration gradients through the entire network of airways and these are involved in such things as Taylor dispersion, augmented diffusion and pedelluft. John, I'm not sure how to translate these concepts into dead space as it applies to bulk flow ventilation.

Marini: I raise it as a question.

MacIntyre: I don't have the answer.

Marini: One last thing. If the alveoli are being ventilated more than usual, small $\mathrm{V}_{\mathrm{Ts}}$ but faster and being ventilated with a high $\mathrm{V}_{\mathrm{D}} / \mathrm{V}_{\mathrm{T}}$, the local epithelial $\mathrm{pH}$ should in that situation be extremely high. There are physiological studies done in the late " 60 s showing that if you do not add $\mathrm{CO}_{2}$ to the inhaled airstream of an animal with high deadspace that is being relatively over ventilated, the lungs fall apart due to inflammation. There may be a lot of contributors here. We're thinking mechanical, and mechanically HFO should be good; but from the ventilation side and gas exchange side it might be inflicting damage or holding back progress.

MacIntyre: It very well could. As I'vethought about this over the years I've divorced myself form the notion of traditional ventilation at the alveolar level. I think this is CPAP with some funky ways of replenishing the 
oxygen and removing the $\mathrm{CO}_{2}$ from the alveolus. It functions much like a CPAP system-CPAP with a "wiggle".

Marini: It's good to think about these things. There is autoPEEP, right, in HFOV?

\section{MacIntyre: It's CPAP.}

Marini: OK, but with the alveolar pressure being higher than the airway opening pressure.

MacIntyre: The mean pressures in the circuit and alveoli are thought to be similar. However, there may be some differences, you can get some standing waves when oscillating around the lung harmonic frequency. Nevertheless, the mean pressures throughout the system are usually not that different.

Marini: Certainly with jet ventilation there's a big difference. With oscillation it's less but I think it's still there. It's a unique type of autoPEEP that never goes away. The alveolar pressure to central airway pressure differential could theoretically drive a circulating flow. It could be one of the mechanisms for ventilation that hasn't been thought about very much.
MacIntyre: Those alveoli are not moving much.

Marini: That's because those alveoli are highly distended, they're at the limit. They can't get big and small.

MacIntyre: They could get small but they don't.

Kacmarek: Convection is still a significant part of this. You showed a picture from the Chang article ${ }^{8}$ that talks about all the different mechanisms. They make a point that convection has a significant role in overall gas exchange. Particularly at the frequency at which we ventilate adults. Neonates no, but in adults when you're at the 4-6 $\mathrm{Hz}$ range convection has a lot to do with gas exchange. You may have a $\mathrm{V}_{\mathrm{T}} 120-130 \mathrm{~mL}$ but it's given 300 times/min you'll have a huge minute ventilation, which is the point that John was making.

\section{REFERENCES}

1. Young D, Lamb SE, Shah S, MacKenzi I, Tunnicliffe W, Lall R, et al; OSCAR Study Group. High-frequency oscillation for acute respiratory distress syndrome. $\mathrm{NEngl} \mathrm{J} \mathrm{Med}$ 2013;368(9):806-813.

2. Ferguson ND, Cook DJ, Guyatt GH, Mehta S, Hand L, Austin P, et al; OSCILlATE Trial Investigators; Canadian Critical Care Trials Group. High-frequency oscillation in early acute respiratory distress syndrome. N Engl J Med 2013;368(9):795-805.

3. Derdak S, Mehta S, Stewart TE, Smith T, Rogers M, Buchman TG, et al; Multicenter Oscillatory Ventilation For Acute Respiratory Distress Syndrome Trial (MOAT) Study Investigators. High-frequency oscillatory ventilation for acute respiratory distress syndrome in adults: a randomized, controlled trial. Am J Respir Crit Care Med 2002;166(6):801-808.

4. Sud S, Sud M, Friedrich JO, Meade MO, Ferguson ND, Wunsch H, Adhikari NK. High frequency oscillation in patients with acute lung injury and acute respiratory distress syndrome (ARDS): systematic review and meta-analysis. Br J Med 2010;340: c2327-c2338.

5. Arnold JH, Hanson JH, Toro-Figuero LO, Gutierrez J, Berens RJ, Anglin DL. Prospective, randomized comparison of high frequency oscillatory ventilation and conventional mechanical ventilation in pediatric respiratory failure. Crit Care Med 1994; 22(10):1530-1539.

6. Bollen CW, Uiterwaal CS, van Vught AJ. Cumulative metaanalysis of high-frequency versus conventional ventilation in premature neonates. Am J Respir Crit Care Med 2003;168(10):1150-1155.

7. Fessler HE, Derdak S, Ferguson ND, Hager DN, Kacmarek RM, Thompson BT, Brower RG. A protocol for high-frequency oscillatory ventilation in adults: results from a roundtable discussion. Crit Care Med 2007; 35(7):1649-1654.

8. Chang HK. Mechanisms of gas transport during ventilation by high frequency oscillation. J Appl Physiol 1984;56(3):553563. 